\title{
Modelling of three dimensional tidal dynamics in Darwin Harbour, Australia
}

\author{
$\mathrm{Li} \mathrm{Li}^{1} \quad$ Xiao Hua Wang ${ }^{2} \quad$ Harvinder Sidhu ${ }^{3}$ \\ David Williams ${ }^{4}$
}

(Received 10 December 2010; revised 28 April 2011)

\begin{abstract}
A three dimensional finite element numerical model, the Resource Management Associates model, is used to simulate the three dimensional hydrodynamics in Darwin Harbour. Observed elevation data are used to calibrate and validate it. The modelling study shows that the hydrodynamics in the region is predominantly tidally driven, with the main constituent being the M2 tide. The amplitude of this tide is damped in the inner harbour because of the tidal choking of the narrow channel connecting it with the outer harbour. When the tide propagates into the entrances of the three arms (East, West and Middle) extending from the channel, its amplitude increases due to the shallower geometry and then decreases in the arms due to the energy dissipation caused by the bottom friction. The tidal current reaches its maximum speed along the channel to the Middle Arm in which the current ellipse becomes rectilinear.
\end{abstract}

http://anziamj.austms.org.au/ojs/index.php/ANZIAMJ/article/view/3765 gives this article, (c) Austral. Mathematical Soc. 2011. Published May 7, 2011. ISSN 1446-8735. (Print two pages per sheet of paper.) Copies of this article must not be made otherwise available on the internet; instead link directly to this URL for this article. 


\section{Contents}

1 Introduction

C104

2 Model description

C106

3 Tidal data and harmonic analysis

C109

4 Results

C110

4.1 Wind forcing . . . . . . . . . . . . . . C110

4.2 Tidal elevation . . . . . . . . . . . . . . . C110

4.3 Tidal current . . . . . . . . . . . . . . . . . C112

5 Discussion

C114

5.1 Tidal choking . . . . . . . . . . . . . . . C114

5.2 Shoaling effect and bottom dissipation ........ . C115

6 Conclusion

C118

References

C120

\section{Introduction}

Developments in the marine industry and coastal management require accurate predictions of the hydrodynamics of coastal seas $[9,11]$ and their harbours and estuaries. Currents and flow patterns are of vital importance to coastal constructions, such as sea dykes and land reclamation projects [14]. A good understanding of sea level variability is essential to any harbour's economic functions, such as marine transportation and port management [15]. Therefore, detailed studies of three dimensional (3D) tidal dynamics are a necessity for any coastal development in a macro-tidal environment, of which Darwin Harbour is an example. 


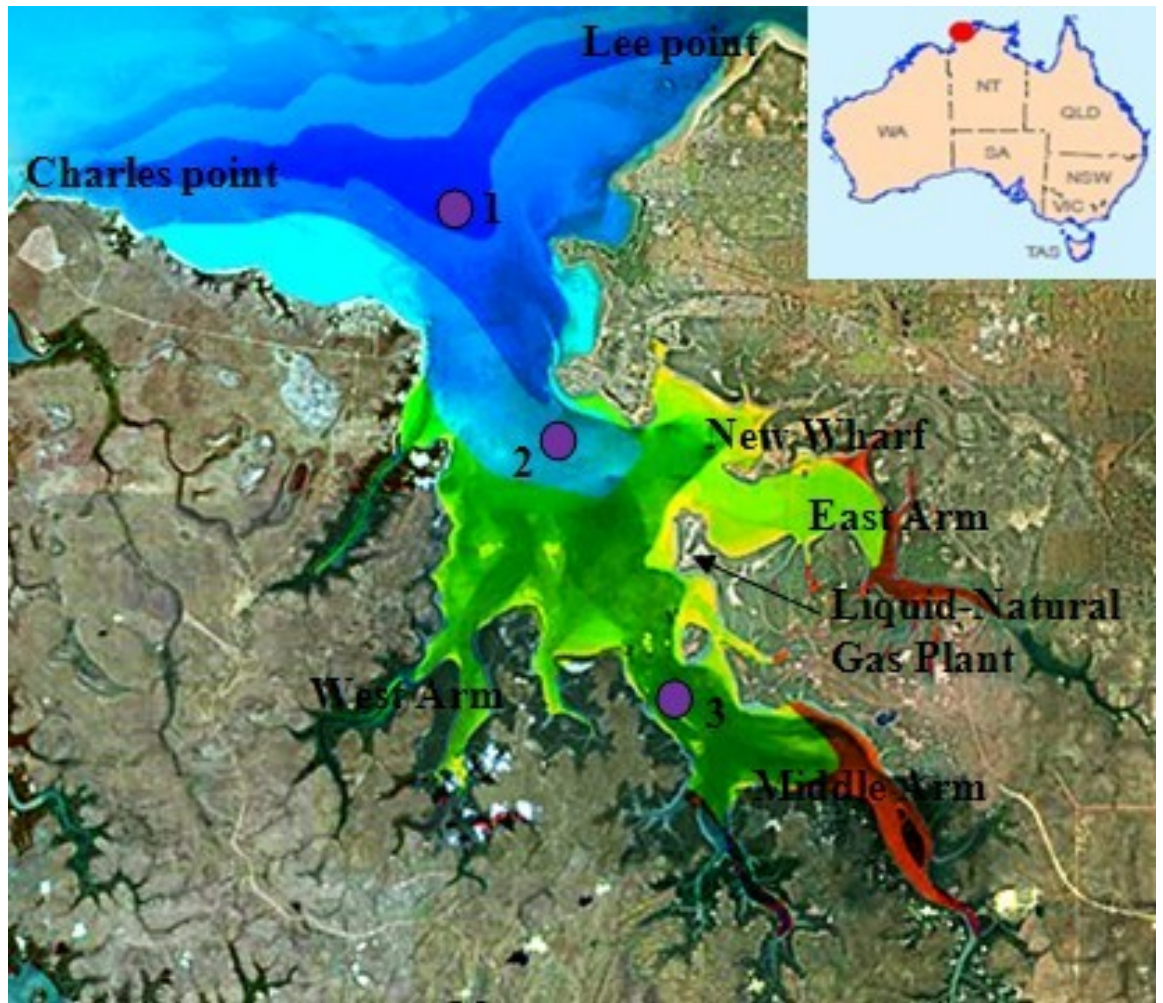

FiguRE 1: Map of Darwin Harbour and model domain.

Darwin Harbour $\left(12^{\circ} 28^{\prime} \mathrm{S}, 130^{\circ} 51^{\prime} \mathrm{E}\right)$ is located in the Northern Territory, Australia (Figure 1). It is characterised by shallow depths of less than 35 metres, extensive tidal flats, wide mangrove forests and relatively strong tides. Charles Point and Lee Point form the outer boundary of the harbour and the uppermost estuary is formed mainly by three rivers running into three arms. The harbour is $50 \mathrm{~km}$ long, comprising the outer and inner harbours, and three arms, namely, the East, West and Middle. The East Arm, which is the location for the proposed East Arm wharf, has a mud bed with a large calcareous sand deposit upstream of the wharf [17]. A liquid natural gas plant LNGP is located near the newly constructed wharf. Darwin Harbour is 
semi-diurnal and macro-tidal, with a maximum tidal range of $7.8 \mathrm{~m}$ and mean spring and neap tidal ranges of $5.5 \mathrm{~m}$ and $1.9 \mathrm{~m}$, respectively [18]. The mean tidal range is $3.7 \mathrm{~m}$ [8]. The harbour has a tropical climate with an annual rainfall of $1500 \mathrm{~mm}$ which occurs mainly in the wet season, from October to April. Despite its macro-tidal characteristics and plentiful rainfall, the harbour is still poorly flushed, especially in the dry season. The headlands and rivers, together with the embayments, create a complicated bathymetry that forms varying current systems, consisting of jets and eddies, in the harbour.

Territorians and visitors to the Top End place a high value on Darwin Harbour which is used for fishing, boating and other recreational pursuits. It also holds significant heritage and cultural value [2]. As a result of Darwin Harbour's importance, more attention has to be given to its hydrodynamics [17] and sediment dynamics [16]. As the locations of siltation are affected by the currents and circulation patterns in the harbour, a good understanding of its detailed hydrodynamics plays a key part in research into its sediment transport and ecosystem dynamics.

To extend the two dimensional work of Williams [17], the present research focuses on the 3D tidal dynamics. A 3D numerical model is developed and used to investigate the tidal characteristics and their spatial variabilities after being validated and calibrated by sea-surface elevation data. The causes of tidal variability are also discussed based on the model results and observation data.

\section{Model description}

A 3D finite element hydrodynamics and water quality model, the RMA model, is used to study variability in tidal characteristics and current profiles. This model is capable of simulating 1D, 2D and 3D coastal waters, such as estuaries, bays, lakes and rivers. Variables included in the model are temperature, salinity, current velocities, nutrients and suspended sediment concentration. The finite element method with quadratic approximation is used to solve the 
hydrodynamics governing equations and the advection-diffusion constituent transport equations. The model is developed using a plan form of linear, triangular and quadrilateral isoparametric elements which are defined by 3 , 6 and 8 node points, respectively. In each case, $2 / 3 / 4$ of the nodes are placed at the vertices and $1 / 3 / 4$ nodes on the sides. The exact position of the mid-side node determines the shape of the side. If the location is precisely at the middle, a true straight side is developed. At any other location, a parametric quadratic curve defines the shape. Within an element, quadratic approximations are used to represent the velocities, $u$ and $v$, and salinity, temperature and sediment. However, a linear approximation is used for the depth, h [5].

The model uses a conventional coordinate system in the vertical direction and an orthogonal coordinate system in the horizontal direction. The bottom stress, which is assigned to the first grid point nearest to the bottom, is calculated from a quadratic friction law with an empirical drag coefficient, the minimum value of which is $2.5 \times 10^{-3}$. A wet and dry scheme is employed for the model, that is, where any corner of an element's water depth drops below a nominal minimum value, which is set as $2.0 \mathrm{~m}$. The nodes are automatically removed from the system, since the water level is too shallow to run the three dimensional model. In addition, the two dimensional model is enough to show the tidal dynamics in shallow water. The turbulence closure method used is based on the Smagorinsky closure method [13] while the input value is used directly to control the model. The Chezy coefficients for water, inter-tidal, mangrove area and shoreline are $0.035,0.075,0.040$ and 0.400 , respectively, depending on their bottom characteristics. For the dry section, the Chezy coefficient is 10 and is ignored for the water surface. The turbulent diffusion coefficients associated with the $\mathrm{X}, \mathrm{Y}$ and $\mathrm{Z}$ directions are $0.2,0.1$ and 0.1 , respectively.

A variable horizontal grid is used to specify the geometry. The intervals of the grid range from $0.02 \mathrm{~km}$ near the wharf and along the arms to $2 \mathrm{~km}$ in the outer harbour. The outermost elements in the outer harbour are the first grids to be calculated. The model uses seven vertical layers between the surface 
and the bottom, with the intervals between them increasing in size from the surface. This boundary layer arrangement helps to obtain finer resolutions which is useful for further study on subjects such as sediment dynamics. The minimum water depth is set to $2.0 \mathrm{~m}$ as, if the water is shallower than that, the $3 \mathrm{D}$ elements will collapse to $2 \mathrm{D}$ elements.

The model is forced by tides and initialised with constant values for salinity and temperature of $33 \mathrm{psu}$ and $25^{\circ} \mathrm{C}$, respectively, both with and without winds. These values are typical of the mean temperature and salinity in Darwin Harbour during the dry season. Also, it is assumed that there is no fresh water input from the three arms during the model time, so as to mimic conditions in the dry season. These assumptions result in barotropic conditions in the model, in which isobaric surfaces parallel to isopycnic surfaces, and the pressure gradient force only depends on the sea surface slope. The tidal elevations, $\mathrm{H}(\mathrm{t})$, which include four semi-diurnal (M2, S2, $\mathrm{N} 2, \mathrm{~K} 2$ ) and two diurnal (K1, O1) constants at the free surface, are

$$
H(t)=\sum_{c} f_{c} \zeta_{c} \cos \left[\omega_{c} t+\frac{\pi}{180}\left(V_{c}+\mu_{c}-g_{c}\right)\right],
$$

where $\zeta_{c}$ and $g_{c}$ are the spatially varying amplitudes and phases, respectively (referenced to $12^{\circ} 28^{\prime} \mathrm{S}, 130^{\circ} 51^{\prime} \mathrm{E}$, local time). The subscript $\mathrm{c}$ represents one of the four major constituents, and $f$ and $\mu$ are the nodal factor and nodal angle, respectively. These nodal modulation corrections explain the 18.6 year nodal cycle for the three major lunar constituents [10]. The astronomical argument, $\mathrm{V}$, indicates the initial phase angle of the equilibrium constituents (c) at Greenwich at time $t=0$. The inclusion of these nodal corrections and astronomical argument allows the model to predict tidal elevations in a manner consistent with those of standard tidal analysis methods [1].

Two numerical experiments, with and without wind forcing, are conducted. The tidal elevations observed at the open boundary at 15 minute intervals are used. The wind forcing data, which is used uniformly on the free surface of the simulation area, are from measurements taken by the Bureau of Meteorology every hour. Both model runs are for a period of 30 days. The model achieves 
TABLE 1: Comparisons of amplitudes and phases obtained from observations and model simulations.

\begin{tabular}{|c|c|c|c|c|c|c|}
\hline \multirow{2}{*}{$\begin{array}{l}\text { Harmonic } \\
\text { constituents }\end{array}$} & \multicolumn{2}{|c|}{ Amplitude (m) } & \multirow{2}{*}{$\begin{array}{r}\text { Deviation } \\
(\%)\end{array}$} & \multicolumn{2}{|c|}{ Phase (Deg) } & \multirow{2}{*}{$\begin{array}{r}\text { Deviation } \\
(\%)\end{array}$} \\
\hline & Obser & Simu & & Obser & Simu & \\
\hline Diurnal & & & & & & \\
\hline O1 & 0.3299 & 0.3341 & 1.27 & 190.11 & 182.31 & -4.10 \\
\hline K1 & 0.5835 & 0.5274 & -9.61 & 200.51 & 190.49 & -4.99 \\
\hline Semidiurnal & & & & & & \\
\hline $\mathrm{N} 2$ & 0.3485 & 0.3741 & 7.35 & 228.43 & 217.03 & -4.99 \\
\hline M2 & 1.8545 & 1.8843 & 1.61 & 249.29 & 234.63 & -5.88 \\
\hline $\mathrm{S} 2$ & 0.9603 & 0.9645 & 0.43 & 298.10 & 294.09 & -1.35 \\
\hline K2 & 0.2688 & 0.2625 & -2.34 & 296.02 & 316.49 & 6.92 \\
\hline
\end{tabular}

a quasi-steady state after a few hourly time steps over its entire domain. Hourly values of the elevation and current velocity over the model's run times are used for tidal and current analyses.

\section{$3 \quad$ Tidal data and harmonic analysis}

Tidal harmonic analysis allows the observed tide or tidal current at any place to be separated into basic harmonic constituents using the least square method. Observed sea surface elevation are represented as functions or signals as the superposition of many sinusoidal component tides. The amplitudes and frequencies of the component tides are determined by a harmonic analysis of the measured tide. This approach decomposes the observed and model simulated sea surface level into harmonic constituents for comparison.

The hourly sea level data recorded by the Bureau of Meteorology (Bom) for the years 1992-2009 are analysed in order to study the principal tidal characteristics in the harbour. In addition, observational tidal data are used to validate and calibrate the simulated model. Table 1 shows the amplitudes 
and phases of the main tidal constituents (M2, S2, K1, N2, O1 and K2). Of these, M2 is the predominant tide with an amplitude of $1.85 \mathrm{~m}$ and a phase of 249 degrees. This shows that Darwin Harbour is a semi-diurnal environment. Table 1 also shows comparisons of the amplitudes and phases obtained from observations and simulation results which agree well, with their deviations being within $9.61 \%$ for the amplitude and $6.92 \%$ for the phase, respectively.

\section{Results}

\subsection{Wind forcing}

Wind has often been considered a predominant driving force for sediment resuspension in many estuaries, especially shallow ones [19]. However, according to Metha (1988) [7], an estuary can be classified into one of three different hydrodynamic regimes based on its tidal range, $\Omega$. That study shows that hydrodynamic forces are tidal currents, wind waves and wind currents when $\Omega \leqslant 1.0 \mathrm{~m}$, tidal currents and wind waves when $1.0 \leqslant \Omega \leqslant 3.0 \mathrm{~m}$, and only tidal currents when $\Omega \geqslant 3.0 \mathrm{~m}$. Based on this classification, since the maximum and mean tidal ranges in Darwin Harbour are $7.8 \mathrm{~m}$ and $3.7 \mathrm{~m}$, respectively, sediment re-suspension in the harbour is expected to be driven only by tidal currents. According to experimental results, the eastern and northern velocities are only slightly affected by the wind (Figure 2) and the differences between them are not more than $0.05 \mathrm{~m} / \mathrm{s}$, which agree well with Mehta's classification.

\subsection{Tidal elevation}

Of the six main tidal constituents (M2, S2, K1, N2, O1 and K2) only the M2 tide results are presented below, because, not only is this tide the predominant tidal constituent in the harbour, according to both the observation 

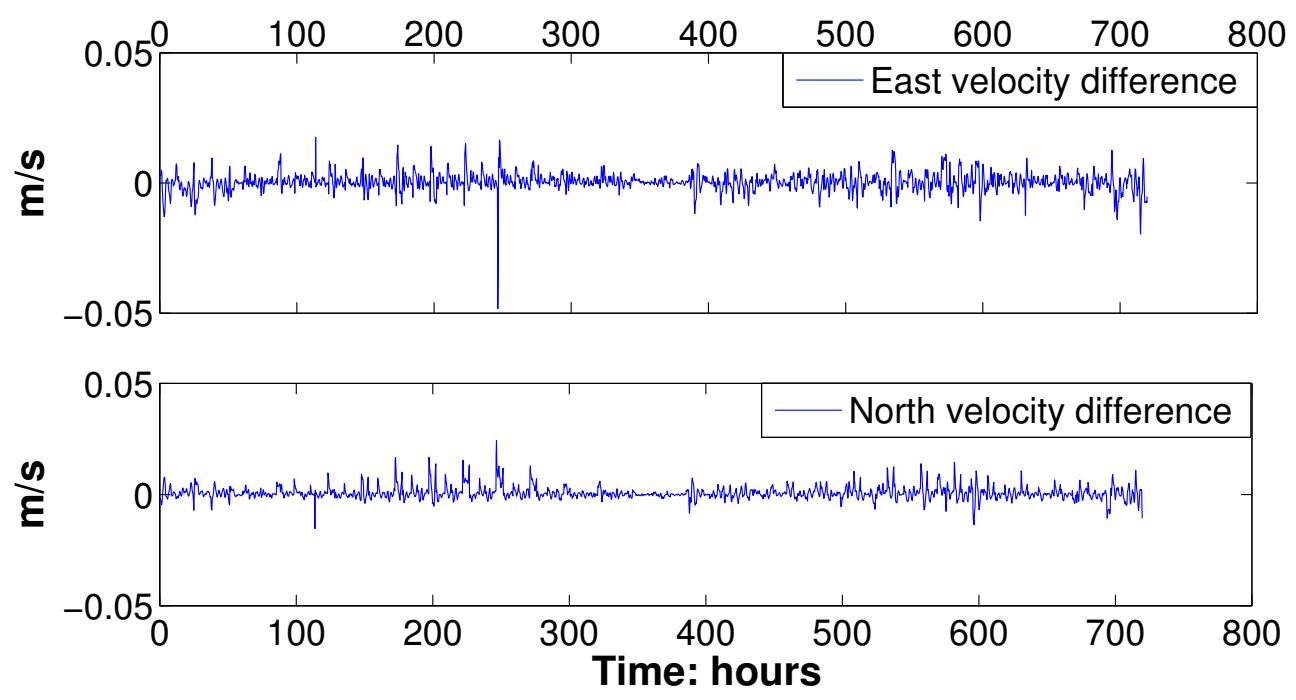

Figure 2: Velocity differences, with and without wind, for east and north components of East Arm from model simulations.

data and simulation results, but it also has tidal characteristics similar to the others.

Figure 3 shows the tidal amplitudes and phases of the M2 tide. The tidal amplitude remains the same in both the inner and outer harbours, and increases slightly from the outer harbour in the northwest to the inner harbour. The amplitude peaks at the entrances of the arms, especially the West and East Arms in the southeast, and then decreases when the tide reaches the end of the arms. As the tide travels through the channel between the outer and inner harbours and then to the arms, its amplitude firstly increases from less than $1.9 \mathrm{~m}$ to about $2.1 \mathrm{~m}$, and then decreases to about $1.8 \mathrm{~m}$. This corresponds to about 5\% higher at the entrances of the arms than it is in the outer harbour and at the end of the arms, while those in the East and Middle Arms are higher than that in the West Arm. The tidal phase increases from $200^{\circ}$ to more than $240^{\circ}$ from the outer harbour to the arms, that is, $40^{\circ}$ or 1.4 hours delayed, when the tide propagates from the boundary towards 


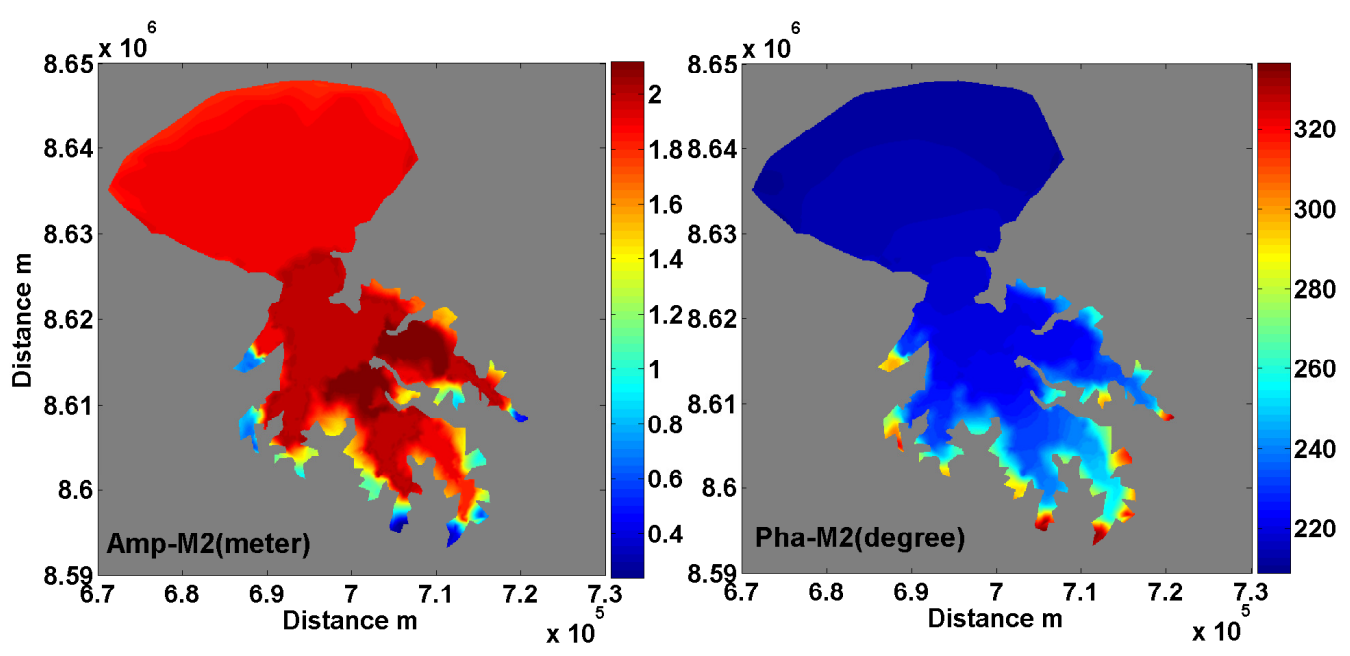

Figure 3: Model simulated M2 amplitudes and phases.

the shallower water and into the arms (Figure 3).

\subsection{Tidal current}

The model predicted M2 tidal current is examined at three stations, which are located in the outer harbour (Station 1), inner harbour (Station 2) and Middle Arm (Station 3); see Figure 1. As the depth of vertical layers is fixed, the number of vertical layers is determined by the water depth. When the water level becomes shallower from the outer harbour to the inner Harbour and the Arms, the top vertical layers need to be removed from the model to correspond to the shallower depth. So Station 1 in the outer harbour has more vertical layers than Station 2 and 3 in the inner harbour and the Arm respectively. Figure 4 shows the variabilities of the tidal current ellipses, both horizontally and vertically. The major axis of the surface current is $0.4 \mathrm{~m} / \mathrm{s}$ at Station $1,0.8 \mathrm{~m} / \mathrm{s}$ at Station 2 and $0.6 \mathrm{~m} / \mathrm{s}$ at Station 3 . The current ellipse is less eccentric in the outer harbour than in the inner harbour and arms. 

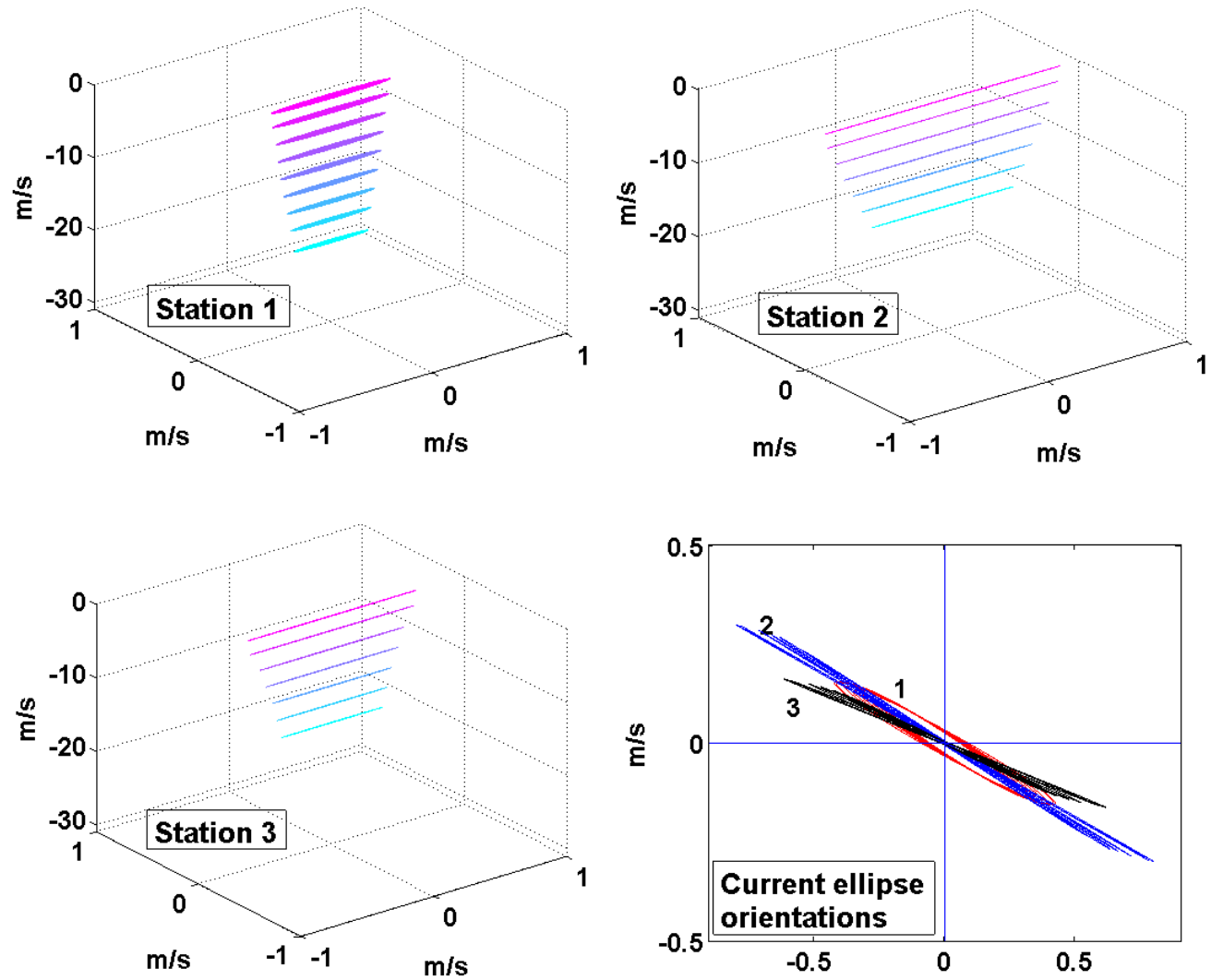

FiguRE 4: Vertical variations in tidal current ellipses and their orientations at three stations. 
The current direction is roughly northwest-southeast horizontally, and the inclinations are slightly smaller in the outer harbour.

From the surface to the bottom, the current amplitude decreases most dramatically in the Middle Arm (Station 3) by 41\%. Near the wharf (Station 2), the current maximum speed decreases by $40 \%$ and, in the outer harbour (Station 1) by $38 \%$. As the surface water above the bottom boundary layer is less affected by the bottom friction, the water in the outer harbour, which is deep, experiences the smallest decrease in its maximum current speed. As the Middle Arm is shallow, the current velocity shear is the strongest at Station 3. The currents from the different layers are in roughly the same northwest-southeast direction from the surface to the bottom, again indicating the controlling effect of the shoreline.

\section{Discussion}

\subsection{Tidal choking}

In the above experiments, the model results show obvious differences in the amplitudes and phases of the tidal constituents among the outer and inner harbours, and the arms. The principal reason is discussed below.

Darwin Harbour comprises a wide outer harbour, a relatively small and shallow inner harbour and three narrow, twisting shallow arms. The inner harbour is connected to the outer harbour by a narrow channel. This is a typical tidal choking system, as described by Byun et al. [1]. Tidal choking commonly occurs in micro-tidal coastal lagoons and bays with shallow depths and narrow channel widths $[3,6]$.

In order to examine the tidal choking process in Darwin Harbour, two experiments were conducted using the same model setup, except for the geometry. When the arms are removed, the water storage capacity of the inner harbour 
is smaller than before. When the amplitude in the inner harbour is increased by approximately $0.05 \mathrm{~m}$ from that simulated by the original experiment, no

phase difference is predicted between the outer and inner harbours (Figure 5a). The main reason for the absence of the phase difference is that the inner harbour water storage capacity is reduced, resulting in no effects due to tidal choking. When the narrow channel is widened, as shown in Figure 5b, the amplitude is also increased in the inner harbour for the same reason.

\subsection{Shoaling effect and bottom dissipation}

When the tide reaches the entrance of the arms, its amplitude increases because of the shallower geometry, but reduces when water travels into the ends of the arms, as shown in Figure 4. In order to examine the amplitude and phase patterns in the arms, the M2 tide energy distribution is discussed. The time averaged, tidal energy density per unit area is calculated from the model elevation and velocity by

$$
E=\frac{1}{4} \rho\left[g \zeta^{2}+h\left(u^{2}+v^{2}\right)\right]
$$

where $\rho$ is the water density, and $u$ and $v$ the amplitudes of the barotropic tidal currents. The energy density of the barotropic tides indicates the amount of energy available for mixing [4].

Since the spatial variabilities of the energy density for the six tidal constituents are similar, only the energy density of the M2 tide is presented. The highest values of the potential energy occur at the entrances of the East and Middle Arms and those of the kinetic energy in the narrow channel and Middle Arm (Figure 6). The energy of the M2 tide is reduced towards the ends of the arms. This result suggests that increases in the M2 amplitude at the entrances of the arms is not due to resonance, but the shoaling effect. When the islands are removed (Figure 7), the amplitude at the entrances of the arms is not as large as shown in Figure 4 due to a reduction in the shoaling effect. 


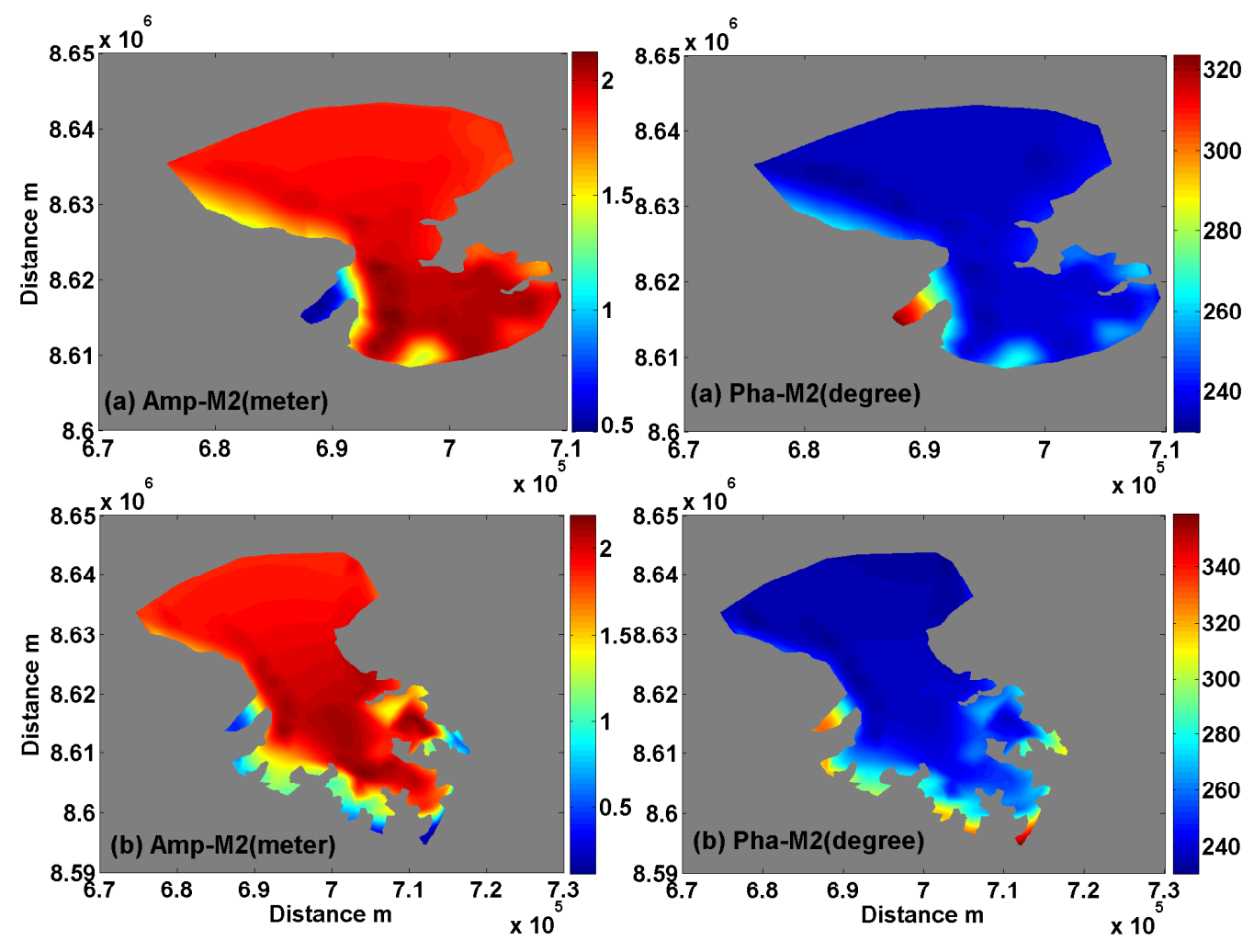

FiguRE 5: Model simulated amplitudes and phases from experiments: (a) arms removed; and (b) channel widened. 


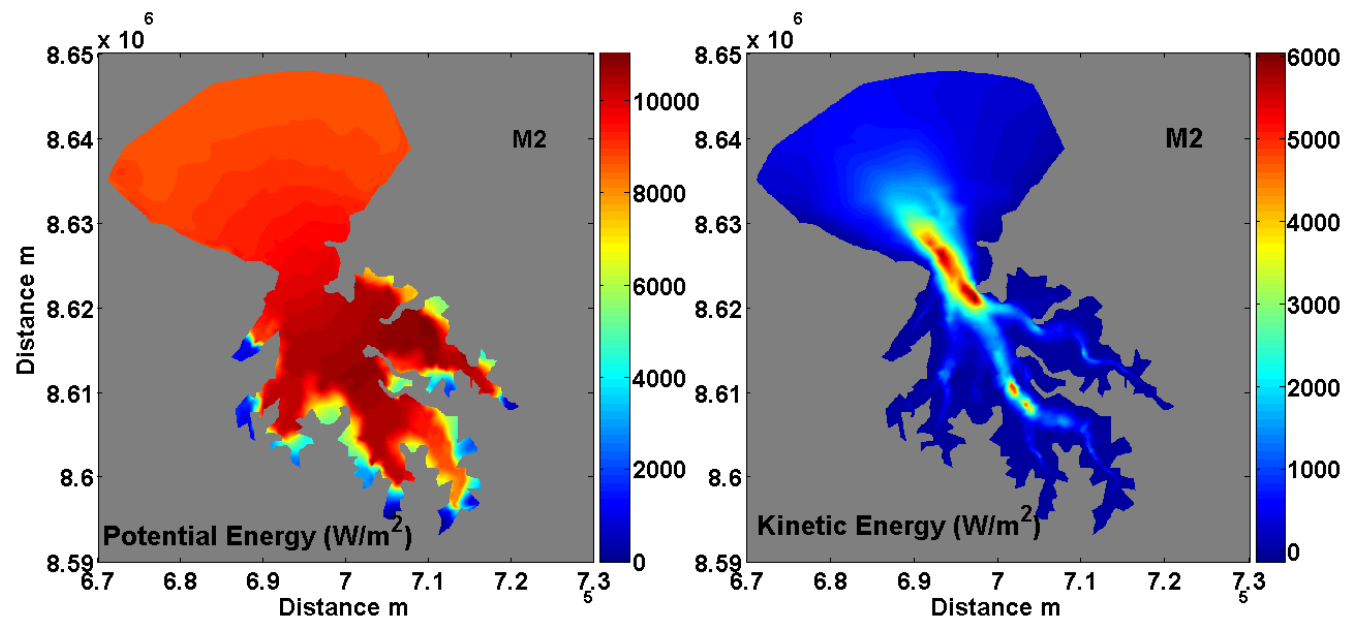

Figure 6: Model simulated potential and kinetic energies for M2.

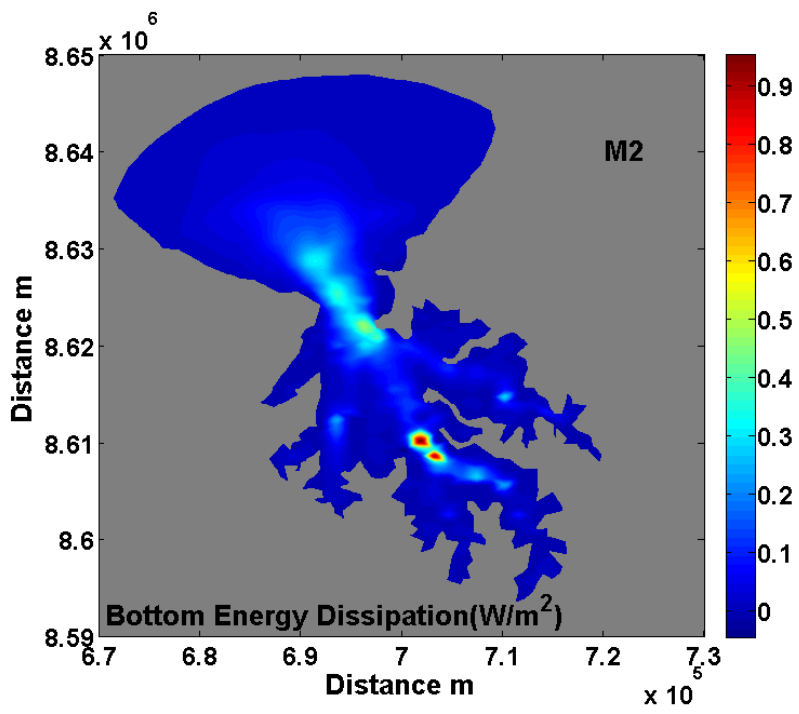

Figure 7: Model simulated bottom energy dissipation. 
The turbulent energy dissipation is calculated by Simpson [12]

$$
\varepsilon=\frac{1}{T-T_{0}} \int_{T_{0}}^{T} \tau_{b} U_{b} d t
$$

where $\tau_{b}$ is the bottom shear stress, $U_{b}$ the velocity near the bottom, $T_{0}$ the initial time, and $\mathrm{T}$ the terminal time.

The tidal dissipation rates at the bottom in the narrow channel are more than $0.3 \mathrm{~W} / \mathrm{m}^{2}$, especially in the Middle Arm where the bottom energy dissipation rate is as high as $0.9 \mathrm{~W} / \mathrm{m}^{2}$. This result demonstrates that the narrow channel and Middle Arm play key roles in energy dissipation. In addition, there is relatively strong energy dissipation, from 0.1 to $0.3 \mathrm{~W} / \mathrm{m}^{2}$, in all three arms (Figure 8). Therefore, a large amount of energy is consumed in the narrow channel and shallow arms which may well explain the dampened amplitude when the water reaches the ends of the arms. Especially in the Middle Arm, where the energy dissipation is as high as $0.3 \mathrm{~W} / \mathrm{m}^{2}$, the amplitude experiences a more significant decrease than in the East and West Arms (Figure 3).

\section{Conclusion}

A 3D RMA model was used to simulate the 3D tidal dynamics in Darwin Harbour after being calibrated and validated by observed elevation data. According to the model and observations, the main forcing for the current is the tides, with the wind playing a minor part in the hydrodynamics. The main tidal constituent is the M2 tide, the amplitude of which remains the same in both the inner and outer harbours because of the tidal choking effect. The study also shows that the shoaling effect causes increases in the tidal amplitude at the entrances of the three arms. The maximum tidal current is found along the channel and in the Middle Arm, while the current ellipse becomes rectilinear in the narrow channel and arms. 


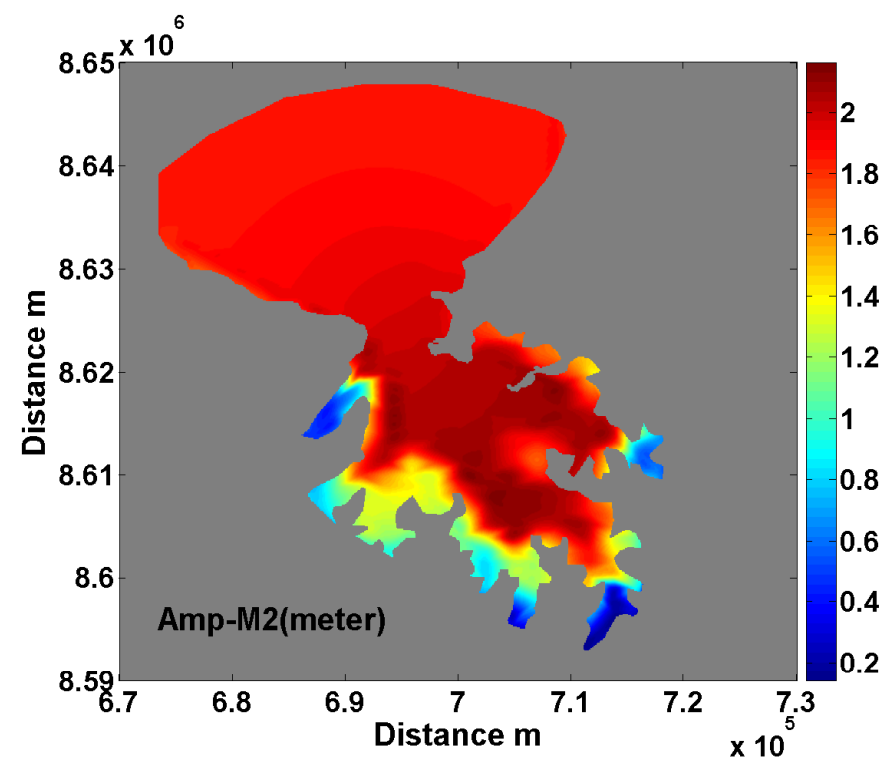

Figure 8: Model simulated M2 tidal amplitudes when islands removed. 
As the characteristics of tidal dynamics play vital roles in future studies of sediment dynamics and biological processes, a detailed consideration of the hydrodynamics for these studies, as well as for coastal construction, is necessary.

\section{References}

[1] D. S. Byun, X. H. Wang, and P. E. Holloway. Tidal characteristic adjustment due to dyke and seawall construction in the Mokpo Coastal Zone, Korea. Estuarine, Coastal and Shelf Science, 59(2):185-196, 2004. doi:10.1016/j.ecss.2003.08.007 C108, C114

[2] J. Fortune and J. Drewry. Darwin Harbour region report cards 2009. Aquatic Health Unit, Department of Natural Resources, Environment, The Arts and Sport. Palmerston NT 0831, page 62, 2009. http:www.nt.gov.au/nreta/water/aquatic/index.html C106

[3] A. M. Hoguane, A. E. Hill, J. H. Simpson, and D. G. Bowers. Diurnal and tidal variation of temperature and salinity in the Ponta Rasa mangrove swamp, Mozambique. Estuarine, Coastal and Shelf Science, 49(2):251-264, 1999. doi:10.1006/ecss.1999.0499 C114

[4] P. E. Holloway and M. A. Merrifield. Internal tide generation by seamounts, ridges, and islands. J. Geophys. Res., 104(C11):25937-25951, 1999. doi:10.1029/1999jc900207 C115

[5] 1. P. King. Chapter 2: Advection diffusion equations for transport, pages 1-7. Resource Modelling Associates, Sydney, Australia, 2009. C107

[6] B. Knoppers, K. Bjorn, and J.P. Carmouze. Trophic state and water turn-over time in six choked coastal lagoons in Brazil. Biogeochemistry, 14(2):149-166, 1991. doi:10.1007/bf00002903 C114 
[7] A. J. Mehta. Laboratory studies on cohesive sediment deposition and erosion, pages 427-445. Springer Verlag, Berlim, 1988. C110

[8] M. G. Michie. Distribution of foraminifera in a macrotidal tropical esturay: Port Darwin, Northern Territory of Australia. Australian Journal of Marine and Freshwater Research, 38:249-259, 1987. http:// www.publish.csiro.au/?act=view_file\&file_id=MF9870249.pdf C106

[9] Robert J. Nicholls. Analysis of global impacts of sea-level rise: a case study of flooding. Physics and Chemistry of the Earth, Parts $A / B / C$, 27(32-34):1455-1466, 2002. doi:10.1016/S1474-7065(02)00090-6 C104

[10] D. T. Pugh. Tides, Surges and Mean Sea-Level. John Wiley and Sons, New York, 1987.

http://eprints.soton.ac.uk/19157/1/sea-level.pdf C108

[11] D. J. Reed. Sea-level rise and coastal marsh sustainability: geological and ecological factors in the Mississippi delta plain. Geomorphology, 48(1-3):233-243, 2002. doi:10.1016/S0169-555X(02)00183-6 C104

[12] J. H. Simpson and J. R. Hunter. Fronts in the Irish Sea. Nature, 250(5465):404-406, 1974. doi:10.1038/250404a0 C118

[13] J. Smagorinsky. General circulation experiments with the primitive equations: I. the basic experiment. Mon. Wea. Rev., (91):99-164, 1963. C107

[14] C. Viseras, J. Fernández, F. García-García, J. Soria, M. Calvache, and P. Juregui. Dynamics of sedimentary environments in the accelerated siltation of a reservoir: the case of Alhama de Granada, southern Spain. Environ Geol, 56:1353-1369, 2009. doi:10.1007/s00254-008-1231-2 C104

[15] Kathelijne M. Wijnberg. Environmental controls on decadal morphologic behaviour of the Holland coast. Marine Geology, 189(3-4):227-247, 2002. doi:10.1016/S0025-3227(02)00480-2 C104 
[16] D. Williams. Part 1:hydrodynamics and sediment transport. Technical report, Australian Institute of Marine Science, Arafura Timor Research Facility, 2009. C106

[17] D. Williams, W. Ewolanski, and S. Spagnol. Hydrodynamics of Darwin Harbour, chapter 26, pages 461-476. Springer, in The Netherlands, 2006. C105, C106

[18] C. D. Woodroffe, K. N. Bardsley, P. J. Ward, and J. R. Hanley. Production of mangrove litter in a macrotidal embayment, Darwin Harbour, N.T., Australia. Estuarine, Coastal and Shelf Science, 26(6):581-598, 1988. doi:10.1016/0272-7714(88)90035-2 C106

[19] L. D. Wright, J. D. Boon, J. P. Xu, and S. C. Kim. The bottom boundary layer of the bay stem plains environment of lower chesapeake bay. Estuarine, Coastal and Shelf Science, 35(1):17-36, 1992. doi:10.1016/S0272-7714(05)80054-X C110

\section{Author addresses}

1. Li Li, School of Physical, Environmental and Mathematical Sciences, University of New South Wales at Australian Defence Force Academy, Northcott Drive, Canberra, ACT, 2600, Australia. mailto:li.li@student.adfa.edu.au

2. Xiao Hua Wang, School of Physical, Environmental and Mathematical Sciences, University of New South Wales at Australian Defence Force Academy, Northcott Drive, Canberra, ACT, 2600, Australia.

3. Harvinder Sidhu, School of Physical, Environmental and Mathematical Sciences, University of New South Wales at Australian Defence Force Academy, Northcott Drive, Canberra, ACT, 2600, Australia. 
4. David Williams, Australian Institute of Marine Science, Arafura Timor Research Facility, Casuarina, NT, 0811,AustraLIA. 